\title{
Exercises to reduce musculoskeletal disorders in dentist: A review
}

\author{
Shaik Ali Hassan ${ }^{1}$, Francis Pratyusha ${ }^{2}$, Sumit Bhateja $^{3 *}$, Geetika Arora ${ }^{4}$ \\ ${ }^{1}$ Dental Surgeon, ${ }^{2}$ Private Practitioner, ${ }^{3} \mathrm{HOD},{ }^{4}$ Reader,,${ }^{1,3}$ Dept. of Oral Medicine and Radiology, ${ }^{4}$ Dept. of Public Health Dentistry, \\ ${ }^{1,3}$ Manav Rachna Dental College, Faridabad, Haryana, ${ }^{2}$ Francis Maxilofacial and Dental Clinic, Telangana, ${ }^{4}$ Inderprastha Dental College, \\ Ghaziabad, Uttar Pradesh, India
}

*Corresponding Author: Sumit Bhateja

Email: bhateja.sumit@gmail.com

\begin{abstract}
As the profession of dentist makes them work for more in dental seats due to visibility and small working area. This is expanding the pervasiveness of musculoskeletal issue in dental specialists. In this article we will emphasize more on simple exercise that can reduce the musculosketal disorders.
\end{abstract}

Keywords: Musculoskeletal disorders, Dentist, Ergonomics, Exercise.

\section{Introduction}

Dentist work cooperatively consistently to address the issues of their patients. While giving oral treatments can be profoundly fulfilling, dental experts are additionally at raised danger of musculoskeletal issue. All things considered, they should be aware of utilizing basic necessary measures during the work as this may cause many future problems. Ergonomics is the study of planning the occupation to oblige the worker, as opposed to truly forcing the representative to adapt to the occupation. Dentist must consider adjusting undertakings, operatories, instruments, and gear to help decrease physical weight on their bodies and dispose of numerous possibly genuine, debilitating business related musculoskeletal issue. ${ }^{1}$ Musculoskeletal problem cause the most drastic effect on body parts as they damage that can't be treated properly. ${ }^{1-4}$ Dentist are especially have to get the needle by bending their back, bend their back for cavity preparation and bend their head towards the oral cavity for long time this causes problems. Introduction to these elements expands dentist hazard for injury be that as it may, appropriate working environment ergonomics can assist with decreasing these dangers. ${ }^{1-4}$

Musculoskeletal issue are a critical word related medical problem among human services providers. ${ }^{5-8}$ In a crosssectional investigation that included specialists, doctors, and dental specialists, the most elevated pervasiveness of musculoskeletal agony was accounted for by dental specialists at $61 \% .^{5}$ Additionally, $60 \%$ of dental specialists with musculoskeletal scatters had issues in more than one site. $^{5}$ Another exploration study exhibited that the predominance of general musculoskeletal torment among oral wellbeing experts ran from $64 \%$ to $93 \% .{ }^{9}$ Investigators found that musculoskeletal issue among dental and dental cleanliness understudies were restricted to explicit destinations. In general, the outcomes recommended that musculoskeletal issues speak to a critical weight for oral wellbeing professionals. ${ }^{9}$ Multisite musculoskeletal problems in dentists are brought about by the requirement for operator during treatment and long working hours with tedious repeating movement. The most generally announced musculoskeletal issue in dentists are carpal passage disorder, tendonitis, rotator sleeve wounds, epicondylitis, trigger finger, muscle strains, and lower back injuries. Hayes et $\mathrm{al}^{4}$ evealed that dental specialists experienced agony regularly in the back (36.3\% to $60.1 \%)$ and neck (19.8\% to $85 \%),{ }^{10}$ while the hand and wrist districts were the most common destinations for torment among dental hygienists $(60 \%$ to $69.5 \%)^{11}$

The dental work is one that can unleash destruction on your back and cause postural issues if not tended to with suitable activities. For all who are working right now is their set up resembles while treating a patient, it is normally a comparative set up from dental specialist to dental specialist, where they are on a stool with wheels, regularly with no back help, with their spine twisted around and marginally turned to the other side, and the shoulders came in. ${ }^{12}$ To initially make an all the more ergonomically right set-up, consider a dental seat with back help for times where you are conversing with the patient or rounding out administrative work. ${ }^{13}$ You will need to make it a propensity to sit tall in your seat, as though a string is gently pulling your head nearer to the roof. Your ear lobe to be stacked over your shoulders and your shoulders stacked over your hips. This position decreases weight on the lower back and bears, which are in any case under consistent worry from being adjusted. ${ }^{14}$

The vibration brought about by certain instruments likewise adds to musculoskeletal clutters. ${ }^{15}$ The utilization of ultrasonic scalers and cleaning handpieces may cause neck, shoulder, and back torment because of the delayed sitting required, holding a physical burden with flexion of the neck and trunk, and support of poor posture. ${ }^{16}$ Oral wellbeing experts frequently keep up static and ungainly stances of in any event 40 minutes, which is legitimately identified with neck, bear and back pain. ${ }^{17}$

\section{Warm-up}

Ought to be accomplished for 10 minutes and ought to incorporate absolute body developments and extending.

\section{Exercise period}

1. Power: Should be at 70 percent pulse most extreme (HRmax-220-age). One should practice till their pulse 
arrives at 70 percent HRmax. This will be to some degree hard to the individual.

2. Length: 20-30 minutes.

3. Recurrence: 3-4 times each week.

4. method of activity: Dentists can pick exercises they appreciate which can be strolling, biking, running, swimming, stair climbing or weight preparing. ${ }^{18}$

\section{Chill off period}

5-10 minutes entire body developments and extending.

Various exercises for dental professionals includes:-

\section{Wall sliding}

Remain with your back against a divider. Keep your heels, glutes, shoulders and the rear of your head as near the divider as could be expected under the circumstances. While keeping your abs somewhat contracted and your shoulder bones withdrew back and down (press your shoulder bones together and keep up the crush all through the whole development). Spot the rear of your upper arms, lower arms and hands over your head and on the divider. While keeping those three focuses in contact with the divider attempt to slide the three focuses down and bring your elbows into your sides. Presently rehash by sliding your hands up the divider and keeping the three focuses as near the mirror as could be expected under the circumstances (Fig. 1). Move gradually here and there the divider and attempt to rehash multiple times, two times per day. ${ }^{19}$

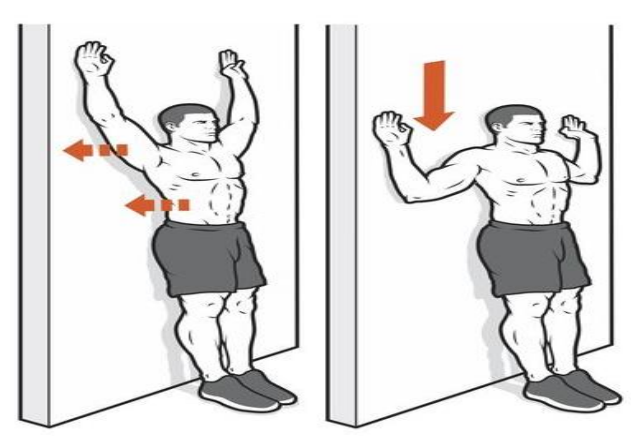

Fig. 1: Wall sliding exercise

\section{Stretching of chest}

The foremost muscles of the shoulder can get exceptionally tight from being adjusted internal throughout the day. To counter this we have to extend these muscles. While remaining in an entryway, place one foot advance and bring your arms up to put within your lower arm, and your palm against the sides of the entryway. Your elbow ought to be at around a 90-degree edge and your upper arms corresponding to the floor. Gradually present your chest until you feel a light stretch in the front of your chest and the front of your shoulders (Fig. 2). Hold the light stretch for 30 seconds, two times per day. ${ }^{20}$

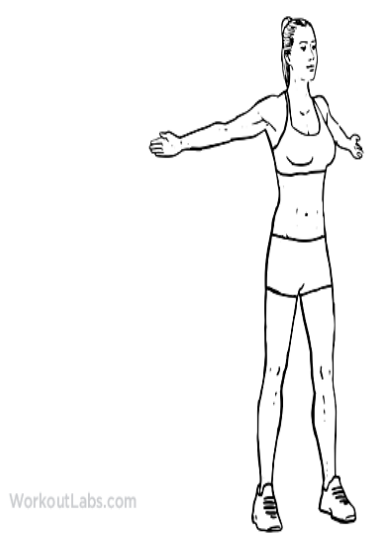

Fig. 2: Stretching of chest

\section{Hip flexing}

The hip flexors are a gathering of muscles found in the front of your hips. The hip flexors help to present your knee and upward. Sitting in a dental seat for extensive stretches of time cause these muscles to fix. We can counter this snugness by extending these muscles. While remaining with your face away from a steady article that is around the tallness of the base of your glute. Twist your knee and reach back to put the highest point of your left foot on the article while keeping your knees in toward the body as contradict to flared out wide from one another. Keep on pushing your correct foot ahead so it is somewhat ahead. Stand tall and include a slight recline while getting your left glute. You should feel a light stretch in the front of your left hip. Hold the stretch for 30 seconds two times per day and rehash on the correct side (Fig. 3). Recall not to overstretch it. You are just reclining somewhat and doing a light glute constriction to support the stretch. ${ }^{21}$

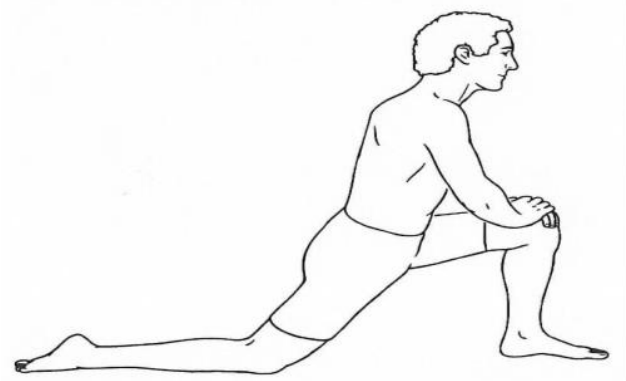

Fig. 3: Hip flexing

\section{Thoracic extension}

Bowing forward while treating patients can add to poor stance all through the spine by over stretching and debilitating this region. At the point when this occurs, our spine gets adjusted and seems, by all accounts, to be slouched over. Doing thoracic augmentations will assist with keeping an upstanding stance and keep the center bit of the spine pleasant and solid. Start by setting your hands and knees on the floor. Right now position on the floor hold your left palm down to the floor straightforwardly under your left shoulder. Your knees ought to be bowed on the floor at a 90-degree point. Your hips ought to be stacked right on your knees. Spot your correct palm on the rear of your head and point your 
correct elbow to turn internal, carrying it as near your left elbow as could be expected under the circumstances. When you get as near your left elbow or even touch it, open up your spine by turning your correct elbow away from your left elbow. Stretch out the correct elbow as far as possible of your range and press your shoulder bones together behind you. At that point pivot your correct elbow back in to one side elbow (Fig. 4). Thoracic expansions ought to be rehashed multiple times on each side. ${ }^{22}$

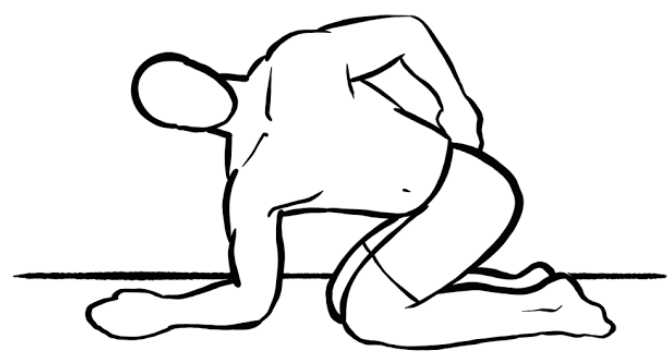

Fig. 4: Thoracic extension

\section{Plank exercise}

Lower back issues are basic in dentistry. This is frequently the consequence of a frail center, which can come from one's situation on the dental seat. A board is an incredible trial of center quality. Start by putting your feet on the floor and your elbows straightforwardly under your shoulders. At that point lift your knees, hips and chest off the ground. You need to be in an orderly fashion from your lower legs to your head. Once right now is essential to keep up steady breathing and attempt to last in the event that you can before your body begins to shake (Fig. 5). An objective you may consider for a board practice is to begin by doing it for 30 seconds and afterward working as long as two minutes. ${ }^{23}$

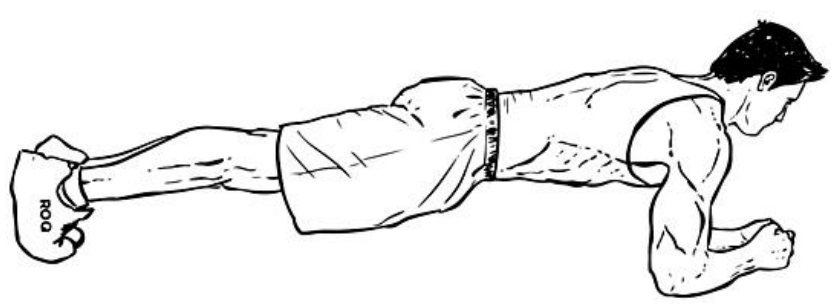

Fig. 5: Plank exercise

\section{Knee raise exercise}

Another activity to help reinforce a debilitated center is the twofold knee raise. Frequently individuals go straight into a straight leg raise which is a lot for what they need before all else and can be extremely exceptional on your spine. I prescribe beginning with a twisted knee position. Start by laying on your back with your hands to your sides. Bring your thighs up with the goal that your hips are at a 90-degree edge. Presently twist your knees with the goal that they are likewise at a 90-degree edge. This is your beginning position. From here, keep up your 90-degree knee position and gradually bring down your hips until your thighs arrive at a 45-degree edge. Do whatever it takes not to go lower than this from the outset as your lower back will begin to curve and strip off the floor. You just need to bring down your legs as far as possible to guarantee that your lower spine stays on the floor (Fig. 6). Attempt this for two arrangements of 10 reiterations and afterward work up to 15 redundancies. ${ }^{24}$
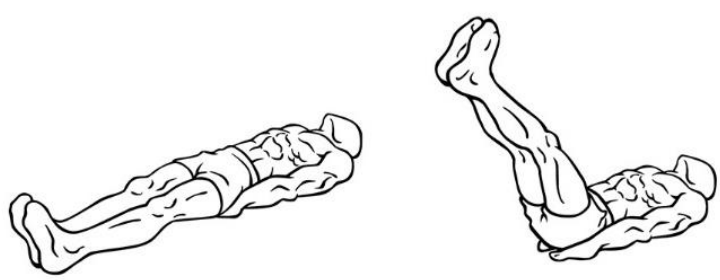

Fig. 6: Knee raise exercise

\section{Superman exercise}

Untruth inclined on the floor or an activity tangle with your arms and legs expanded. Utilizing the muscles of your back, at the same time raise your arms, legs, and chest off the floor, holding the constriction at the top for one entire second. Note: Squeeze your lower back for ideal outcomes, breathing out at the highest point of the development. Right now, should resemble a hero flying. Gradually lower your arms, legs, and chest to the beginning position while breathing in. Rehash for 15-20 reiterations in three sets. The activity can be altered by utilizing each arm and leg in turn. Hoist the correct arm and left leg at the same time while concentrating on accomplishing greatest augmentation, extending at your fingers and toes (Fig. 7). Rehash on the contrary side. ${ }^{25,26}$

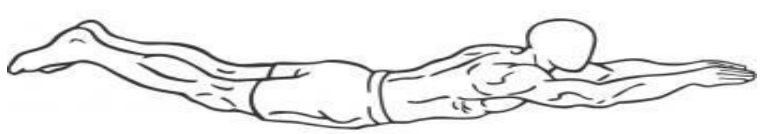

Fig. 7: Superman exercise

\section{Conclusion}

Through this article I would like to tell that the exercise is important for dental professionals as there is more work which is related to back bone which leads to musculoskeletal disorders like most common is back ache, shoulder pains. The exercises mentioned above reduce the pain and help the dental professional to deliver proper time to patient without strain.

\section{Source of Funding}

None.

\section{Conflict of Interest}

None.

\section{References}

1. United States Department of Labor: Occupational Safety and Health Administration. Ergonomics: The Study of Work. Washington, DC; 2000:1-14.

2. Al-Hourani Z, Nazzal M, Khader Y, Almhdawi K, Bibars AR. Work-related musculoskeletal disorders among Jordanian 
dental technicians: Prevalence and associated factors. Work. 2017;56:617-23.

3. Occhionero V, Korpinen L, Gobba F. Upper limb musculoskeletal disorders in healthcare personnel. Ergonomics. 2014;57:1166-91.

4. Hayes MJ, Taylor JA, Smith DR. Predictors of work-related musculoskeletal disorders among dental hygienists. Int J Dent Hyg. 2012;10:265-9.

5. Rambabu T, Suneeth K. Prevalence of work related musculoskeletal disorders among physicians, surgeons and dentists: A comparative study. Ann Med Health Sci Res. 2014;4:578-82.

6. Park JH. Association among work-related musculoskeletal disorders, job stress, and job attitude of occupational therapists. Occup Ther Health Care. 2017;31:34-43.

7. Muaidi QI, Shanb AA. Prevalence causes and impact of work related musculoskeletal disorders among physical therapists. $J$ Back Musculoskelet Rehabil. 2016;29:763-9.

8. Macdonald W, Oakman J. Requirements for more effective prevention of work-related musculoskeletal disorders. BMC Musculoskelet Disord. 2015;16:293.

9. Hayes M, Cockrell D, Smith D. A systematic review of musculoskeletal disorders among dental professionals. Int $J$ Dent Hyg. 2009;7:159-65.

10. Valachi B, Valachi K. Preventing musculoskeletal disorders in clinical dentistry: Strategies to address the mechanisms leading to musculoskeletal disorders. J Am Dent Assoc. 2003;134(12):1604-12.

11. Khan S, Chew K. Effect of working characteristics and taught ergonomics on the prevalence of musculoskeletal disorders amongst dental students. BMC Musculoskelet Disord. 2013;14:118-25.

12. Hayes MJ, Taylor JA, Smith DR. Predictors of workrelated musculoskeletal disorders among dental hygienists. Int J Dent Hyg. 2012;10(4):265-9.

13. Liss GM, Jesin E, Kusiak RA, White P. Musculoskeletal problems among ontario dental hygienists. Am J Ind Med. 1995;28(4):521-40.

14. Ylipaa V, Arnetz BB, Preber H. Predictors of good general health, well-being, and musculoskeletal disorders in swedish dental hygienists. Acta Odontol Scand. 1999;57(5):277-82.

15. Osborn JB, Newell KJ, Rudney JD, Stoltenberg JL.

Musculoskeletal pain among minnesota dental hygienists. $J$ Dent Hyg. 1990;64(3):132-8.
16. Marklin RW, Cherney K. Working postures of dentist and dental hygienists. J Can Dent Assoc. 2005;33:133-6.

17. Morse T, Michalak-Turcotte C, Atwood-Sanders M, et al. A pilot study of hand and arm musculoskeletal disorders in dental hygiene. J Dent Hyg. 2003;77(3):173-9.

18. Chaiklieng S, Suggaravetsiri P. Ergonomics risk and neck shoulder back pain among dental professionals. Philadelphia: Elsevier: 2015;4900-05.

19. Ahearn DJ, Sanders MJ, Turcotte C. Ergonomic design for dental offices. Work. 2010;35(4):495-503.

20. Finkbeiner BL. Four-handed Dentistry: A handbook of clinical application and ergonomic concepts. Prentice Hall: Upper Saddle River NJ. 2001:69-74.

21. Hokwerda OO, Wouters JAJJ, de Ruijter RAGR. Ergonomic requirements for dental equipment, Guidelines and recommendations for designing, constructing and selecting dental equipment. [Internet] 2006 [Updated 2007; Cited 2007 Dec.] Available from: http://www.optergo.com/images/Ergonomic_req_april2007.pdf

22. Dong H, Loomer P, Barr A, La Roche C. The effect of tool handle shape on hand muscle load and pinch force in a simulated dental scaling task. Appl Ergon. 2007;38(5):525-31.

23. Jones AC, Forsythe S. Functional training for dentistry: an exercise prescription for dental health care personnel. CDA J. 2005;33(2):37-45.

24. Talpos-Niculescu C, Lungeanu D, Anghel M, Stratul S, Bucur A. The role of physical exercise in preventing musculoskeletal disorders caused by the dental profession. Timisoara Med J. 2010;60:293-98.

25. Carolyn Kisner, Lynn Allen Colbby. Therapeutic exercise Foundations and Techniques. New Delhi: Jaypee Brothers; 1996.

26. Milerad E, Ericson MO, Nisell R, Kilbom A. An electromyographic study of dental work. Ergonomics. 1991;34(7):953-62.

How to cite this article: Hassan SA, Pratyusha F, Bhateja S, Arora G. Exercises to reduce musculoskeletal disorders in dentist: A review. J Oral Med, Oral Surg, Oral Pathol, Oral Radiol 2020;6(1):32-5. 